\title{
The Bemusing Broadened Face - A Case of Bilateral Masseter Muscle Hypertrophy
}

\author{
Sunmith Santannavar ${ }^{1}$, Gowri P Bhandarkar ${ }^{2}$, Geon Pauly ${ }^{1 *}$, Roopashri Rajesh Kashyap ${ }^{2}$, \\ Raghavendra Kini ${ }^{3}$, Prasanna Kumar Rao ${ }^{4}$ \\ ${ }^{1}$ Postgraduate Student, Department of Oral Medicine and Radiology, A J Institute of Dental Sciences, \\ Kuntikana, Mangaluru, Karnataka, India \\ ${ }^{2}$ Reader, Department of Oral Medicine and Radiology, A J Institute of Dental Sciences, Kuntikana, Mangaluru, \\ Karnataka, India \\ ${ }^{3}$ Professor and Head, Department of Oral Medicine and Radiology, A J Institute of Dental Sciences, Kuntikana, \\ Mangaluru, Karnataka, India \\ ${ }^{4}$ Professor, Department of Oral Medicine and Radiology, A J Institute of Dental Sciences, Kuntikana, \\ Mangaluru, Karnataka, India
}

*Corresponding Author: Geon Pauly, 1. Postgraduate Student, Department of Oral Medicine and Radiology, A J Institute of Dental Sciences, Kuntikana, Mangaluru, Karnataka, India, Email: geonpauly@gmail.com

\begin{abstract}
An abnormal enlargement of any part of the body, whether symptomatic or asymptomatic is always a cause of concern. Hypertrophy of the masseter muscle is a relatively unfamiliar benign condition. It can exist unilaterally or bilaterally. There may or may not be associated pain, but most frequently these cases arrive at our table for cosmetic reasons. Clinically it presents as an enlargement of one or both masseter muscles. Most patients complain of facial asymmetry; however, symptoms such as trismus, protrusion, and bruxism may also occur. This paper reports a case of a symptomatic bilateral masseter hypertrophy.
\end{abstract}

Keywords: Masseter Muscle; Hypertrophy; Idiopathic; Conservative Management.

\section{INTRODUCTION}

The masseter muscle is thick quadrate essential muscle for mastication which arises from the zygomatic arch and inserts into the inferior lateral aspect and angle area of the mandibular ramus and is located laterally to the mandibular ramus, and thus plays an important role in facial aesthetics. A hypertrophied masseter will alter facial lines, generating discomfort, and negative cosmetic impacts for many patients ${ }^{[1]}$. The aetiology of this condition remains obscure, but some authors have correlated it to gum chewing, psychological disorders, and tempo roman dibular joint disorders, to name a few ${ }^{[2]}$.

Hereby, we report a case of a bilateral masseter hypertrophy in a 32-year-old patient, who reported with a complain of unexplained pain on one side of the face.

\section{CASE REPORT}

A 32-year-old medically fit male patient reported to our department with a chief complaint of pain on the left side of the face since 4-5 years. He gave a history of visiting a dentist 3-4 years back, where the diagnosis was established as atypical facial pain and was advised pain-killers. Patient gives a history of noticing a progressive gradual swelling on the left side of the face, first noted 8-9 years back, with associated mild intermittent pain which was first noted about 4-5 years back.

His medical, dental and family histories were non-contributory. Extra-oral examination showed an obvious bilateral swelling centred over the mandibular angle, more pronounced on the left than the right side. Patient was totally unaware of the swelling on the right side [Figure 1]. Palpation indicated that the swollen tissue was normal in tone and non-tender on right side, while elicited slight tenderness on the left side, especially on palpating the left masseter muscle. Mandibular movements were in the normal range. When the patient was asked to clench, the swelling became more prominent and firm. There was no history of temporomandibular joint clicking or any other joint discomfort. 


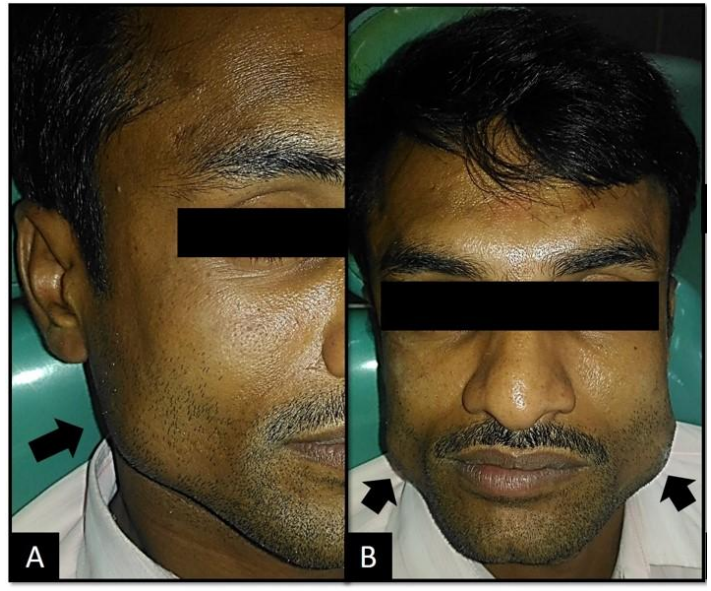

Figure1. Bilateral Masseter Hypertrophy: Right Side View (A), Bilateral View (B).

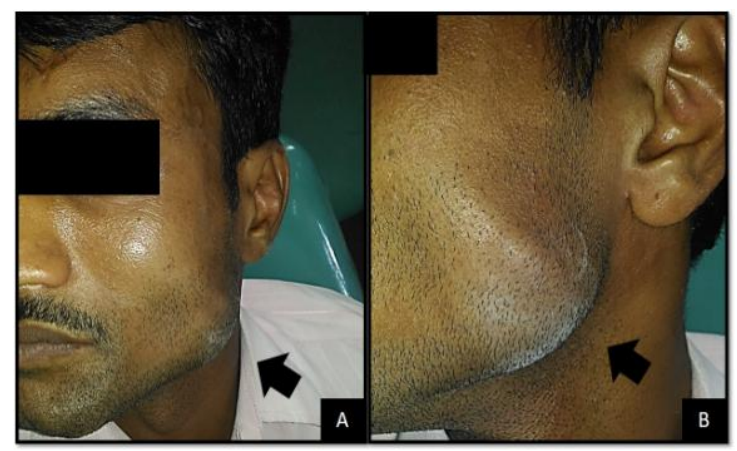

Figure2. A, B - Masseter Hypertrophy on the Left Side

A provisional diagnosis of bilateral masseter hypertrophy was established and patient was advised for an ultrasound scan. The scan report revealed focal hypertrophy of bilateral masseter muscle, left more pronounced than right, with cervical lymphadenopathy. Patient was prescribed muscle relaxant tablets (Flexon MR (B) for 1 week and recalled which showed considerable reduction in pain. The patient was asked to continue the use of muscle relaxant, advised a soft diet and was recalled after 1, 3 and 6 months with the total disappearance of the symptoms.

\section{DISCUSSION}

The term 'hypertrophy' is defined as the enlargement of an organ or tissue resulting from an increase in the size of its cells. Literature mentions masticatory muscle hypertrophy as cases that may affect the temporalis muscle, the medial pterygoids, the masseter muscle individually or in a variety of combinations. Masseter hypertrophy is thus considered a rare disorder wherein there is a persistent asymptomatic enlargement of one or both masseter muscles ${ }^{[3]}$. Hypertrophy of the masseters was first described by Legg in 1880 . There are a few theoretical explanations for the aetiology of masticatory muscle hypertrophy, but the precise aetiology is not clear and inconspicuous to differentiate so in most of the cases considered as idiopathic. One of the main triggering factor are the para-functional habits such as bruxism induced by a wide array of causes such as psychosocial stress, anxiety, malocclusion and sleep disorders. Most case have been seen to occur in isolation or with temporalis muscle hypertrophy. On the flip-side, temporalis hypertrophy without hypertrophy of masseters is found to be extremely rare ${ }^{[4]}$.

The parameters that help establish an effective diagnosis are: Clinical examination, directed interview, panoramic x-ray and ultrasound. The chair-side diagnostic tests mainly consist of palpating the muscle with the fingers while the patient clenches his/her teeth so that the muscle is more prominent during contraction. With the patient's mouth slightly open the muscle is more relaxed, which aids in extra-oral palpation using both hands, for it will outline the precise intramuscular location of the hypertrophy ${ }^{[5]}$. In our case too, the preliminary diagnosis was ascertained by palpating the fibre of masseter muscle during clenching.

The differential diagnosis that can be considered for such a case are lipoma, benign or malignant muscle tumours, vascular tumours and perhaps the most anatomically relatable; parotid tumours [6]. As mentioned by Teixeira et al., they classified masseter hypertrophy under as two types: congenital or familial type, and acquired type which could be accounted under as functional hypertrophy ${ }^{[7]}$. There are numerous management modalities for masseter hypertrophy. This can be divided under as nonsurgical and surgical. Some of the extensively used methods include: Use of mouth guards, analgesics, muscle relaxant, anxiolytic drugs, and physical therapy. An important part of the treatment also includes dental restorations and occlusal adjustments to correct premature contacts. Also, in patients where in the cause is induced by psychosocial stress, psychological counselling may be the first-line of treatment, while other modalities can be given as an adjuvant ${ }^{[8]}$.

To suffice, masseter muscle hypertrophy is a benign condition that usually does not require surgical intervention. Misdiagnosed cases due to lack of familiarity with this entity may lead to unnecessary biopsies, explorative surgeries and even radiotherapy for suspected parotid tumours [9]. 


\section{CONClusion}

It is aptly said, "Every problem has its solution, but the real problem lies in finding it." Masseter muscle hypertrophy is a disease of obscure aetiology that may involve anybody. Although the diagnosis is eminently clinical, complementary examinations may aid in differential diagnosis against other conditions. The chosen conservative treatment mainly depends upon underlying aetiology and on the flip side surgical treatment rely heavily on surgeon experience and skill, if at all surgery is required.

\section{REFERENCES}

[1] Al-Ahmad HT, Al-Qudah MA. The Treatment of Masseter Hypertrophy with Botulinum Toxin Type A. Saudi Med J. 2006; 27: 397-400.

[2] Rispoli DZ, Camargo PM, Pires JL, Fonseca VR, Mandelli KK, Pereira MA. Benign Masseter Muscle Hypertrophy. Braz J Otorhinolaryngol 2008; 74: 790-3.

[3] Parente E, Silvares M, Naegele M, Ribeiro D, Andrade M. Surgical Treatment of Bilateral Temporalis and Masseteric Hypertrophy: Report of a Case. Open J Stomatol 2013; 3: 99102.
[4] Chrispal A, Boorugu HK. Benign Masticatory Muscle Hypertrophy. Journal of the Association of Physicians of India. 2009; 57: 764.

[5] Daniel ZR, Paulo MC, José L, Pires JR, Vinicius RF, Karina KM et al. Benign Masseter Muscle Hypertrophy. Rev Bras Otorrinolaringol. 2008; 74(5): 790-3.

[6] Shetty N, Malaviya RK, Gupta MK. Management of Unilateral Masseter Hypertrophy and Hypertrophic Scar-A Case Report. Case Reports in Dentistry. 2012:1-5. ID 521427.

[7] Teixeira VC, Mejia JES. Tratamento Cirúrgico da Hipertrofia Benigna Do Masseter Por Abordagem Intra-Oral. Revista Brasileira De Cirurgia. 1996; 86(4): 165-170.

[8] Bab B, Ozan B, Muolali M, Celebi N. Treatment of Masseteric Hypertrophy with Botulinum Toxin: A Report of Two Cases. Medicina Oral Patología Oral Cirugia Bucal. 2010; 15: 649-52.

[9] Sannomya Ek, Gonçalves M, Cavalcanti MP. Masseter Muscle Hypertrophy - Case Report. Braz Dent J. 2006; 17(4): 1-3.

Citation: Sunmith Santannavar, Gowri P Bhandarkar, Geon Pauly, Roopashri Rajesh Kashyap, Raghavendra Kini, Prasanna Kumar Rao. The Bemusing Broadened Face - A Case of Bilateral Masseter Muscle Hypertrophy. ARC Journal of Dental science. 2017; 2(4): 12-14. doi:dx.doi.org/10.20431/2456-0030.0204004.

Copyright: () 2017 Authors. This is an open-access article distributed under the terms of the Creative Commons Attribution License, which permits unrestricted use, distribution, and reproduction in any medium, provided the original author and source are credited. 